\title{
MIKS UNGARLASED EI TAHA OLLA SOOMEUGRILASED? ANGELA MARCANTONIO JA JOBBIK ÜHES LAUSES
}

2012. aasta septembris toimus Ungaris VI soome-ugri rahvaste maailmakongress. Selle sündmuse järellainetusena käis ka meie meediast põgusalt läbi arusaam, et soome-ugri keelesugulus, mis liidab Eesti, Soome ja Ungari kümnete väikerahvastega Venemaal, on sattunud Ungaris rünnaku alla. Nagu sõnastas selle üks toonane Delfi artikkel, soomeugri keelesugulus olevat Habsburgide vandenõu, mida õige ungarlane ei tunnista (Delfi 2013a). See, eesti kultuuritajus peaaegu teotuslikuna kõlav arusaam ei näi kaugeltki nii ekstreemne ungari keele kontekstis, milles esineb ohtralt turgi keelte mõjusid ja diskussioon ungari keele võimalikust seotusest turgi keeltega on sama vana kui fennougristika ise. Ka poliitilist konteksti vaadates tundub ungari keel nagu hiiglane kääbuste seas: ainus suurkeel, mille kõnelejad moodustavad üle 50 \% kõigist soome-ugri keelte kõnelejatest. Kui teha meelevaldseid seoseid, oleks Ungari saatkonna sulgemine Eestis 2014. aasta septembris, Ungari üha suurenev Moskva-orienteeritus ja (miks mitte) ka soov taaskehtestada surmanuhtlus justkui loomulikud sümptomid Ungari üha suuremale mitte-soomeugrilisusele. Peab siiski nentima, et peaminister Viktor Orbáni poliitikas on „ajalooline keelesugulus fakt, mitte maitse asi" (Delfi 2013b) ja pigem on selle ideoloogia hääletoruks paremäärmuslik Jobbik Magyarországért Mozgalom (Liikumine Parema Ungari Nimel).

Ükski nendest ideedest ei ole sündinud aga tühjale kohale ning teema on aktuaalne ka teaduslikus diskursuses. Praegu valdavaks tunnistatud mudeli kohaselt jagunevad soome-ugri keeled kaheks rühmaks: soome-permi keelerühmaks (mis omakorda jaguneb läänemeresoome, volga ja permi keelteks) ning ugri keelerühmaks. Soome-ugri keeled moodustavad aga osa suuremast uurali keelkonnast, mille teiseks haruks on samojeedi keeled. Kuid see mudel pole kaugeltki lõpuni heakskiitu pälvinud ja välja on pakutud ka mitmeid alternatiivseid teooriaid. Üheks suureks senise hierarhilise keelepuu mudeli kriitikuks on itaalia lingvist Angela Marcantonio, kes leiab, et uurali keelkonnal (ja selle peamisel harul, soome-ugri keelerühmal) puudub piisav ühisosa tõestamaks keelkonna olemasolu. Samas eksisteerib uurali keelkonna alla klassifitseeritud keeltel ohtralt sarnasusi teiste, valdavalt turgi ja jukagiiri keeltega, mida uralistid tavaliselt ignoreerivad võimaliku geneetilise seose kontekstis, kuna need sarnasused on vastuolus uurali keelkonna mudeliga. Sellest kirjutab Marcantonio oma 2002. aasta raamatus "The Uralic Language Family: Facts, Myths and Statistics” („Uurali keelkond: faktid, müüdid ja statistika”), mille lingvistilisest argumentatsioonist annan järgnevalt lühikese ülevaate.

Marcantonio alustab katsetest rekonstrueerida proto-uurali häälikusüsteem ning sõnavara. Moodsatest rekonstruktsioonidest esimene oli Juha Janhuneni 1981. aasta uurimus „Uralilaisen kantakielen sanastosta” („Uurali algkeele sõnavarast”), mis kirjeldab lää- 
nemeresoome, permi ja samojeedi keeltes aset leidnud häälikumuutusi, mis võiksid viia tagasi proto-uurali keeleni, ja toob välja kolme keelerühma sõnade võimalikke etümoloogiaid nende häälikumuutuste tõestuseks. Oluliseks täienduseks oli Pekka Sammallahti 1988. aasta artikkel „Historical phonology of the Uralic languages, with special reference to Samoyed, Ugric, and Permic” („Uurali keelte ajalooline fonoloogia osutusega samojeedi, ugri ja permi keeltele”), mis suutis olemasolevasse rekonstruktsiooni lisada ka ugri keelerühma keeled. Marcantonio leiab aga, et need rekonstruktsioonid on ebaveenvad, kuna kirja pandud häälikumuutused on keerulised ja etümoloogiline materjal, mis peaks häälikumuutusi tõestama, reeglitega paremaks sobimiseks teadlikult kohandatud. Samas pole ka etümoloogiline tõestusmaterjal väga tugev ning sageli on uurijad teinud meelevaldseid tõlgendusi sõnade tähenduses. Need vähesed etümoloogiad, mis on semantiliselt järjepidevad ja häälikumuutustele kohandamata, paneb Marcantonio juhuse, „rändsõnade” (sks Wanderwörte) ning laenamiste arvele. Sageli ilmneb, et hea etümoloogiaga näitel esineb analooge väljaspool uurali keelkonna keeli.

Teisena käsitleb ta laensõna ja paralleelse põlissõna vahel esinevat ebamäärasust - kuigi on vähe etümoloogilist tõestusmaterjali, mis viitaks ühisele proto-uurali keelele, esineb uurali keeltes sageli suur ühisosa teiste, mitte uurali keelkonda kuuluvate keelte sõnavaraga. Neid sarnasusi uralistid aga ignoreerivad kui võimalikku tõestusmaterjali keelte geneetilisest sugulusest ning omistavad need kas laenamise, keelekontaktidest tingitud konvergentsi (sks Sprachbund) või lihtsalt juhusliku kokkusattumuse arvele. Erinevalt proto-uurali rekonstruktsioonidest, mis võtavad arvesse keerulisi ja ebareeglipäraseid häälikumuutusi, on need sarnasused tihti läbipaistvad. Selle tões- tamiseks võrdleb Marcantonio kehaosade ning floora ja fauna proto-uurali rekonstruktsioone ning leiab, et ainult $10 \%-1$ nendest rekonstruktsioonidest puudub vaste mõnes muus, uurali keelkonda mitte kuuluvas keeles (lk 179).

Kolmandana käsitleb ta uurali keelkonna väidetavat iidsust - üks peamisi argumente, miks uurali keelkonnas leidub nii vähe ühist sõnavara ja morfoloogiat, peituvat uurali keele kõrges vanuses. Kuna lahknemine algkeelest toimus nõnda ammu (hinnanguliselt 6000-8000 aastat tagasi), ongi väga raske leida selget ühisosa. Tõendusmaterjaliks uurali keelkonna iidsusest on väidetavalt väga vanad indoeuroopa laenud ja ühisosa taimenimedes, mis kasvasid proto-uurali asustusalal enam kui 6000 aastat tagasi. Marcantonio leiab, et lingvistiline tõestusmaterjal uurali keelkonna iidsusest on ebapiisav, samal ajal kui soome-ugri keelte morfoloogiline areng on täheldatav võrdlemisi hilises perioodis, esimestes kirjalikes allikates: ungari „Halotti beszéd és könyörgés” („Hauakõne ja palve”) XII sajandi lõpust.

Neljandana juhibki Marcantonio tähelepanu ühisosa puudumisele uurali keelte morfoloogilises ülesehituses. Ühisosa pole isegi grammatilistes kategooriates (kui eesti keeles arvatakse olevat 14-15 käänet, siis näiteks teatud handi keele murretes on ainult kaks käänet), rääkimata konkreetsetest käände- või pöördelõppudest. Kui Marcantonio uurib konkreetsete morfeemide (tähenduse) ja leviku vahelist seost, ilmneb taaskord, et uurali ja mitteuurali keelkonna keelte morfoloogilises struktuuris esineb märkimisväärne ühisosa.

Oma väidete tõestuseks kasutab Marcantonio statistilist meetodit, seda nii proto-uurali sõnavara, nt laensõnade, kui ka morfoloogilise süsteemi tasandil. Statistiline meetod on justkui tuleproov selgitamaks välja, kas uurali keeltes leiduv ühisosa on piisav tõestamaks keelkonna olemasolu. Eriti 
oluline on proto-uurali sõnavara statistiline analüüs, kus Marcantonio seob uuritavate sõnade (Marcantonio võtab uurimisobjektiks kehaosadele osundavad sõnad Károly Rédei „Uurali etümoloogilises sõnaraamatus" ning selle osa Janhuneni korpusest, mida Janhunen ise on pidanud kvaliteetsemaks) etümoloogia konsonantide hulgaga sõna tüves ning sõna esinemissagedusega tänapäeva uurali keeltes. Mida lühem on sõna ja mida vähemates sihtkeeltes leidub selle atesteeritud järglasi, seda suurem on tõenäosus, et tegemist on juhusliku kokkusattumusega. Sõnad, mille etümoloogiline seos tundub ka statistiliselt tõenäoline, võtab Marcantonio lähema uurimise alla ning juhib tähelepanu, kui nendel sõnadel esineb paralleele väljaspool uurali keeli või kui etümoloogia semantiline vastavus ei ole lõpuni selge. Alles jäänud vähestest sõnadest, mis on tõepoolest uurali keelkonnale ainuomased ning etümoloogiliselt tugevad, ei piisa Marcantonio meelest eraldiseisva keelkonna tõestamiseks.

Niisiis, kui võtta näidislauseks Mall Hellami tutvustatud Elav kala ujub vee all (ung Eleven hal úszik a víz alatt), siis Marcantonio analüüsi kohaselt oleks see lause rohkem juhuslike tüvede ja ühiste laensõnade kokkulangemine kui tõestus reaalsest keelesugulusest. Sõnad elav / eleven ja all / alatt ei ole statistiliselt olulised, kuna mõlema tüves esineb ainult üks konsonant (lk 150), ning sõna kala / hal on laialt levinud rändsõna, mille algkeelt ei ole võimalik tuvastada (lisaks uurali keeltele esineb see ka oroki ja nanai keeles ( $\chi$ olto), mis kuuluvad hoopis tunguusi keelte hulka) (lk 110, 149).

Lisaks lingvistilistele argumentidele kasutab Marcantonio vähemal määral ka tõestusmaterjali ajaloodokumentidest, antropoloogiast ja geneetikast.

Teaduslik retseptsioon Marcantonio tööle varieerub. Üheks tugevaks toetajaks on Eesti oma uralist Ago Künnap, kes kiidab Marcantonio raamatut „õige- usklike", st traditsionalistlike fennougristide õudusunenäoks (Künnap 2002: 523), „mille mõju uralistikale on raske üle hinnata" (Künnap 2002: 525), ning kelle ideed uurali keelepuu ebatäpsusest vaatavad Marcantonioga paljuski samas suunas. Marcantonio oli ka 2013. aastal toimunud Eesti Keele Instituudi konverentsi „Uralic and Indo-European Language Contacts" üheks peaesinejaks.

Teised arvamused on aga märksa skeptilisemad. Nõnda näiteks kiidab Edward J. Vajda raamatut selle poolest, et see toob esile uralistikas leiduvad murekohad, kuid raamatu tervikliku sõnumiga siiski lõpuni nõus ei ole. Marcantonio statistiline analüüs ei ole piisav tõendus, et kogu uurali keelkonna mudel maha kanda (Vajda 2003).

Sootuks teravam on aga Stefan Georgi kriitika, mis annab Marcantonio tööle hävitava hinnangu, seda nii statistilise meetodi läbiviimise, teistest keelkondadest paralleelide otsimise kui ka lõplike järelduste kohta. Marcantonio raamat on kallutatud, tekitamaks lugejas mulje, nagu tõendeid uurali keelkonna olemasolu kohta on vähem kui tegelikult. Proto-uurali algkeele statistilises analüüsis on teadlikult piiratud Janhuneni korpust ja kehtestatud etümoloogia tugevuse hindamiseks erakordselt karmid kriteeriumid, samas kui leksikoloogilisi paralleele teistest aasia keeltest on otsitud sügavama kriitikameeleta. „Siinkohal paistab silma eelkõige see, et autor, kes varasemalt oli valmis ka kõige väiksemat „ebareeglipärasust” uralistikas kõrgelennuliselt pidama tõendiks uralistika puuduliku olemasoluõigustuse kohta, viskab nüüd - mil see temale sobib, et näidata kui palju väidetavalt leidub uurali sõnu ja morfeeme ka „teistes aasia" keeltes - järsku ja ette hoiatamata igasuguse metodoloogilise ranguse kõrge kaarega üle parda (Georg 2004: 161).

Georg, kes ise on spetsialiseerunud altai lingvistikale, heidab ette Marcantonio asjatundmatust turgi ja draviidi 
keeltes, millest Marcantonio on otsinud paralleele, ning toob pikas arutluses välja mitme Marcantonio etümoloogia ekslikkuse. Võrdlemisi samasuguse järeldusega on ka Janne Saarikivi retsensioon (2004).

Suur osa Georgi kriitika teravusest ei tulene mitte eksimustest lingvistilises analüüsis (kuigi näiteid sellest toob Georg ohtralt), vaid Marcantonio kergelt sensatsioonilisest toonist, mis kuulutab raamatu sisu „revolutsiooniliseks” veel enne seda, kui lugeja on jõudnud sissejuhatusest kaugemale. Marcantonio selgitab võrdlemisi emotsionaalse sõnavaraga oma töö põhjuslikku tagamaad, milleks on võitlus uralistikas kinnistunud arusaamadega, nagu oleks juba XIX sajandi lõpus lõplikult tõestatud (Joseph Budenzi ja Otto Donneri poolt) ungari keele seos soome ning teiste soomeugri keeltega. Marcantonio sõnul polnud see tõestus kaugeltki selge ja oli pigem ajendatud poliitilisest motivatsioonist diskrediteerida Austria keisri alamate hulka kuuluvate ungarlaste võimalik$\mathrm{ku}$ sugulust türklastega. Hiljem on $\mathrm{Bu}$ denzi ja Donneri teadustöö kinnistunud dogmaks, mis takistab ka tänapäeval tunnistamast, Marcantonio arvamusel ilmselget, sugulust ungari ja turgi keelte vahel. „Ungarlaste soome-ugri päritolu sotsiaalpoliitilise eelistatuse alguse saab viia tagasi Ungari olukorrale AustriaUngari kaksikmonarhia (1867-1918) kontekstis, niinimetatud Austria-Ungari kompromissi ajal (lk 52).

Hiljem olevat takistanud paradigmamuutust aga Ungari kuulumine Nõukogude Liidu mõjusfääri. „Uuemal ajal, Vene mõju perioodil, oli teadlastel ohtlik võtta omaks ungarlaste turgi päritolu teooriaid. Tegelikkuses pälvis soome-ugri paradigma Nõukogude Liidu perioodil võimu eelsoosingu" (lk 53).

Vastuolu on sedavõrd suurem, et Marcantonio ideed on leidnud väljundi ungari paremäärmusliku erakonna Jobbik poliitilises retoorikas. Ungari suuruselt teise opositsioonipartei ideoloogia üheks võtmekomponendiks on nn Ungari turanism, mis seob ungarlaste päritolu pigem turgi kui soome-ugri rahvastega. Marcantonio lingvistiline töö annab sellele ideoloogiale tõsise teadusliku tausta. Nõnda leiabki näiteks 2008. aasta karmisõnalisest avalikust pöördumisest Ungari haridus- ja teadusministeeriumile „Välja juurida soome-ugri vale" viite ka Marcantonio teadustööle. Petitsiooni argumentatsioon soome-ugri mudeli eelistamise kohta XIX sajandi saksa kultuuriruumi kontekstis on laias laastus Marcantonioga sama. Ka geneetilisi asitõendeid, mida Marcantonio kasutab teisejärgulisema asitõendina (ning Georg peab häbematuse tipuks), kasutab see pöördumine, tõestamaks, et ungarlased tõepoolest kuuluvad pigem turgi kui soome-ugri rahvaste hulka.

See, kas Marcantonio statistiline analüüs on pöördeliselt paradigmasid muutev, lõplikuks tõestuseks ebapiisav või täielikult vale, jäägu otsustada uralistidele endile. Ehk on Marcantonio teadusliku töö asetamine samasse lausesse Jobbikuga ning "alternatiivsete" teooriate hulka näide just sellisest dogmaatilisest mõtlemisest, mille vastu ta võitleb. Teisalt ei saa mööda tõsiasjast, et kuigi raamatu pealkiri ja sissejuhatav peatükk viitavad uurali keelkonna sisemiste seoste puudumisele, on tegelikkuses peamiseks teemaks pigem ungari keele seotus turgi keeltega. On selgelt ja korduvalt rõhutatud, et senine uurali keelkonna hierarhiline mudel on vale, kuid mis määral ja kuidas täpsemalt, enam nii selge pole. Autor ei paku selget ülevaadet, milliseid keeli on seni peetud ekslikult sugulasteks, milliseid mitte nõnda saab vaid sõrmega järge ajades välja lugeda, et ungari keel kindlasti ei kuulu samasse keelerühma kui handi ja mansi keel (st ugri keelte hulka) (lk 75), samas läänemeresoome ja permi keeled pigem nagu oleksid sugulased (lk 141). Handi ja mansi keel on lähemal samo- 
jeedi keeltele kui ungari keelele (lk 226), kuid samojeedi keelte käändesüsteem on lähedasem jukagiiri keeltele kui soomeugri keeltele (lk 222-223). Saami keeled on mitme keele segu ega sobitu tegelikult ühegi määratluse alla (lk 125-126). Leheküljel 131 kirjutab Marcantonio, et fonoloogilise struktuuri põhjal saab eristada küll läänemeresoome, permi, obiugri, ungari, samojeedi ja saami keelerühmi, kuid ei pea tõestatuks nende geneetilist sugulust ühtsest algkeelest.

Marcantonio viitab järjepidevalt uurali keelkonna „õpikutõlgendusele”, millele tema enda analüüs vastandub. Seda tehes annab ta ka ülevaate erinevatest uurali keelkonna mudelitest ning sõnastab ühe lehekülje ulatuses ka uurali keelkonna kohta kehtivad „põhiteesid”. Kui võrrelda seda 1998. aastal välja antud ja Daniel Abondolo koostatud kogumikuga „The Uralic Languages” („Uurali keeled”), mis on ilmselt põhjalikem inglise keeles ilmunud tervikkäsitlus uurali keelte kohta, on Marcantonio ülevaade mõnevõrra kompaktsem

\section{Kirjandus}

Abondolo, Daniel (koost) 1998. The Uralic Languages. (Routledge Language Family Descriptions.) LondonNew York: Routledge.

Beadvány a finnugor hazugság felszámolásáért, 2008.11.18. http://www. magyarfold.eoldal.hu/cikkek/magyarnyelv/beadvany-a-finnugor-hazugsagfelszamolasaert-.html (22. IX 2015).

Delfi $2013 \mathrm{a}=$ Soome-ugri keelesugulus olevat Habsburgide vandenõu, mida õige ungarlane ei tunnista. - Delfi 10. II.

Delfi $2013 \mathrm{~b}=$ Ungari peaminister Soomes: keelesugulus on ajalooline fakt, mitte maitse asi. - Delfi 13. V.

G e o r g, Stefan 2004. Rezension A. Marcantonio: The Uralic Language Family. Facts, Myths and Statistics. - Fin- ja mitte-eriala lugejale ka hoomatavam. Paratamatult mõjub Eesti haridusega lugejale kummastavalt väide, et soomeugri keele-mudel on saksa imperialismi ja nõukogude tagurlikkuse vili. Samas pole - kui kasutada jälle Delfi retoorikat - alternatiivsed mudelid ungari keele päritolu kohta siiski pelgalt „populistlikud legendid”, mida "teadlased peavad üsna jõuetult pealt vaatama" (Delfi 2013a). Vahest ongi Marcantonio raamat edukaim selles, et seab kahtluse alla komparatiivse meetodi kriitikavaba kasutamise lingvistikas ja näitab mõnevõrra ebamugavalt, kuidas rahvuslik identiteet mõjutab teaduslikke tõekspidamisi. Kas Eesti tõepoolest tunneks rahvusvahelisel tasandil nii palju muret väikerahvaste olukorra üle Venemaal, kui oleks teaduslikult tõestatud, et keelesugulasi meil teisel pool Laadogat siiski ei ole? Miks läheb meile näiteks neenetsite saatus palju rohkem korda kui kettide oma?

NORMAN KUUSIK

nisch-Ugrische Mitteilungen, kd 2627, lk 155-168.

K ü n n a p, Agu 2002. Õigeusklike õudusunenägu. - Keel ja Kirjandus, nr 7, lk 523-525.

M a r c a n t o n i o, Angela 2002. The Uralic Language Family: Facts, Myths and Statistics. (Publications of the Philological Society 35.) Oxford-Boston: Blackwell.

S a a rikivi, Janne 2004. Review: Angela Marcantonio, The Uralic Language Family: Facts, Myths and Statistics. Journal of Linguistics, $\mathrm{kd} 40$, nr $1, \mathrm{lk}$ 187-191.

Vajd a, Edward J. 2003. Review: The Uralic Language Family: Facts, Myths, and Statistics. - The Canadian Journal of Linguistics, kd 48, lk 117-121. 